\title{
The current situation in the approach to osteoporosis in older adults in Turkey: areas in need of improvement with a model for other populations
}

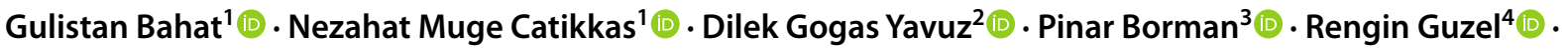 \\ Jean Yves Reginster ${ }^{5}$
}

Received: 23 March 2021 / Accepted: 8 November 2021

(c) International Osteoporosis Foundation and National Osteoporosis Foundation 2021

\begin{abstract}
Purpose The total number of older adults in Turkey is striking, amounting to around 8 million, and this translates into considerably higher numbers of cases of osteoporosis (OP) and fractures in older adults. In this article, we outlined the current situation of OP in older adults in Turkey and investigated the differences between Turkey and a representative developed European country (Belgium), in terms of the screening, diagnosis, and treatment of OP. Our intention in this regard was to identify areas in need of improvement and subsequently to make a clear call for action to address these issues.

Methods Herein, considering the steps related to the OP approach, we made a complete review of the studies conducted in Turkey and compared with the literature recommendations.

Results There is a need for a national osteoporotic fracture registry; measures should be taken to improve the screening and treatment of OP in older males, such as educational activities; technicians involved in dual-energy X-ray absorptiometry (DXA) scanning should undergo routine periodic training; all DXA centers should identify center-specific least significant change values; all older adults should be considered for routine lateral dorsolumbar X-ray imaging for the screening of vertebral fractures while ordering DXA scans; the inclusion of vertebral fracture assessment (VFA) software in DXA assessments should be considered; screening using a fracture risk assessment tool (FRAX) algorithm that is specific to Turkey should be integrated; the fortification of foods with vitamin D is required; the high fracture risk by country-specific FRAX algorithm and the presence of falls/high fall risk should be integrated in reimbursement terms; and finally, more "fracture liaison services" should be established.

Conclusion We suggest that the practical consideration of our suggestions will provide considerable support to the efforts for combating with the adverse consequences of OP in society. This approach can be subsequently modeled for other populations to improve the management of OP globally.
\end{abstract}

Keywords Osteoporosis · Current situation · Turkey · Older · Improvement

\author{
Abbreviations \\ BMD Bone mineral density \\ DXA Dual-energy X-ray absorptiometry
}

\section{Gulistan Bahat}

gbahatozturk@yahoo.com

1 Division of Geriatrics, Department of Internal Medicine, Istanbul Medical School, Istanbul University, Capa, 34093 Istanbul, Turkey

2 Division of Endocrinology and Metabolism, Department of Internal Medicine, Marmara Medical School, Marmara University, Istanbul, Turkey

3 Department of Physical Medicine and Rehabilitation, Hacettepe Medical School, Hacettepe University, Ankara, Turkey
eGFR Estimated glomerular filtration rate

ESCEO Economic evaluation of osteoporosis and osteoarthritis 


$\begin{array}{ll}\text { FLS } & \text { Fracture liaison service } \\ \text { FRAX } & \text { Fracture risk assessment tool } \\ \text { IOF } & \text { International osteoporosis foundation } \\ \text { LSC } & \text { Least significant change } \\ \text { NOF } & \text { National osteoporosis foundation } \\ \text { OP } & \text { Osteoporosis } \\ \text { PMR } & \text { Physical medicine and rehabilitation } \\ \text { PTH } & \text { Parathyroid hormone } \\ \text { TENS } & \text { Transcutaneous electrical nerve stimulation } \\ \text { VFA } & \text { Vertebral fracture assessment } \\ \text { WHO } & \text { World Health Organization }\end{array}$

\section{Introduction}

Osteoporosis (OP) is a bone disease that is associated with increased fragility risk due to reduced bone mass and/or microarchitectural deterioration, the global prevalence of which is on the increase, along with fracture rates. In 1990 , it was projected that the global incidence of the most debilitating type of fragility fracture - that of the hip - will have increased by $310 \%$ in men and $240 \%$ in women by 2050 [1]. Furthermore, it is estimated that $1 / 3$ of all postmenopausal women and $1 / 5$ of all males aged $>50$ will suffer from an osteoporotic fracture. The prevalence of OP increases significantly with aging, and studies have reported that around $75 \%$ of all osteoporotic fractures occur in women aged 65 and over [2]. There is a well-known global aging in societies not only in developed countries, but also in developing countries. In Turkey, a developing country in Eastern Europe, those aged $\geq 65$ years accounted for $9.5 \%$ of the total population in 2020 , and while this rate is lower than that of many developed countries, it still equates to around 8 million people, which is greater than the total populations of some European countries. The absolute number of older adults in Turkey can thus be considered striking, and this translates into considerably higher OP and fracture numbers in older adults in the country. While the hip fracture rates are relatively lower in Turkey than those in Europe, the incidence has increased considerably over the last 20 years. In the 2009 FRACTURK study conducted in Turkey, it was estimated that around 24,000 hip fractures occur each year, and the figure was predicted to rise to $64,000 /$ year by 2035 [3].

Hip and vertebral fractures are associated with high morbidity and mortality risk, and several studies have reported that mortality risk increases after a hip and vertebra fracture $[4,5]$. Almost $20-30 \%$ of all hip fracture patients die within 1 year of the fracture [6], and only $40-70 \%$ of the survivors achieve pre-fracture mobility and normal daily living activity and independence levels. While vertebral fractures remain silent in most cases, they are three times more common than hip fractures, and the presence of one vertebral fracture indicates a 5 times greater risk of hip fracture and a 2-3 times greater risk of other fractures [7]. The pain and mobility problems associated with fractures lead to the increased use of resources associated with longterm institutional care and rehabilitation. Beaudart et al. reported that healthcare costs remain higher than the prefracture level for the five years following the fracture [8].

There are currently several effective modalities to counter osteoporotic fractures, and early intervention is expected to decrease fractures and disability/mortality rates, and to reduce health expenditures. If osteoporotic fractures can be prevented, savings of around $50 \%$ in healthcare costs may be achieved [9]. That said, studies have suggested that most osteoporotic patients are not adequately diagnosed and treated [10], making OP a significant public health problem.

Although the incidence of osteoporotic fractures increases exponentially after age 50, these individuals are less likely to be screened and treated for OP. Estimation approaches, such as the fracture risk assessment tool (FRAX), are based on mean survival expectancy and do not involve decision guidance to help patients with a life expectancy of less than 10 years. Despite the shorter life expectancy, the risk of fracture in a 90-year-old female is greater than that of a 70-year-old. The benefits of oral OP medications become evident within 6-12 months, and the benefit of actions against fall prevention emerges promptly. Economic models have revealed that treating older females even with a life expectancy of less than 2 years may be cost-effective [11]; hence, the efficacy and efficiency of preventing OP-related fractures increase in older adults. This is in contrast to the loss of benefit from other screenings, such as those for cancer. Older individuals are less likely to be screened and treated for OP, although the social burden from OP is much higher in older adults.

The management of OP in older adults involves different aspects, including screening, diagnosis, and treatment. In this article, we outline the current situation of OP in older adults in Turkey and compare the findings with the documented international recommendations of a developing country. Thus, the differences between Turkey and a representative developed European country (Belgium) in the screening, diagnosis, and treatment of OP are identified, along with areas in need of improvement. We conclude by making a clear call for action on the possible areas of improvement.

\section{Osteoporosis in older adults - the current situation in Turkey}

\section{Significance of osteoporosis and its burden}

The prevalence of OP in females and males aged $>50$ is $27.2 \%$ and $22.2 \%$ in Turkey, respectively [9]. In those aged 
50-64 years, the frequency of hip fracture is similar between genders [9], while $73 \%$ of hip fractures are reported to occur in females aged $>75$ years. The 10 -year probability of hip fractures increases with age. The International Osteoporosis Foundation (IOF) identified a high hip fracture risk in females in Turkey [12], although there is no national fracture registry that would allow the better documentation of osteoporotic fractures in the country.

One important factor is that of OP awareness. In a 2005 study assessing the level of awareness of OP in osteoporotic patients, conducted in six different geographical regions of the country, 576 consecutive patients were evaluated with dual-energy X-ray absorptiometry (DXA) for bone mineral density (BMD). The respondents were asked if they had any knowledge or opinions about OP, and if so, from what sources did they get the information, and it was found that only $54 \%$ of the respondents were aware of OP [13]. In another study, investigating the prevalence of OP in Thrace region of Turkey in 2004, 19.2\% of the 620 participants aged 40-89 years had never heard of the term "osteoporosis" and $74 \%$ could not define it. Of those who knew about OP, one-third had heard about it from a doctor, one-third from a friend, and one-third from the media, and of the total, 23.2\% had a history of previous BMD measurements. Accordingly, this study revealed a continued lack of public awareness of the condition [14].

Osteoporosis (OP) is usually ignored in male patients, leading to a lack of diagnosis and treatment, although screening is recommended in men in the presence of risk factors. In a study conducted by Kucukler et al. in the city of Corum, Turkey, an OP screening of specifically male nursing home residents and male community-dwelling adults aged $\geq 65$ years was conducted using DXA and lateral thoracolumbar spine X-ray. The screening results revealed previously unknown OP in $25.3 \%$ and $8.8 \%$ of the nursing home residents and community-dwelling older adults, respectively, as well as $27.8 \%$ silent vertebral fractures ( $\geq 65$ years) [15]. Older males are thus disregarded for OP screening in Turkey.

In the epidemiological FRACTURK study, it was reported that $1 / 7$ of all females aged $>50$ would suffer from a hip fracture in their remaining life [3]. In a study of 120 cases of hip fracture in Turkey, the mortality rate was reported to be $29.2 \%$ in the first year, $33.3 \%$ over 2 years, and $36.7 \%$ over 3 years [16], while a further study found that between 2003 and 2006, only $20 \%$ of the patients that had suffered from hip fractures had been diagnosed and received treatment for OP [17]. It has also been stated that in line with the reported lack of improvement in OP awareness rates in our country, no improvement efforts has been made. In a multicenter study conducted in 2019 in Turkey, it was found that $82 \%$ of patients who underwent hemiarthroplasty did not receive treatment against OP, even after a fracture [18].
In a systematic review of adults aged 50-89 in Turkey, the cost of OP-related fractures related to hospitalizations, DXA tests, hip fracture surgeries, prescribed medications, and loss of productivity was calculated, and it was revealed that $\mathrm{OP}$ tended to be inadequately treated, despite the timely diagnosis, and more than $75 \%$ of high-risk patients were not started on treatment at all. The devised model predicted the occurrence of 255,183 osteoporotic fractures in 2019, with a yearly cost of around US455 million and suggested that around 1.35 million fragility fractures will occur over the next 5 years, leading to healthcare expenditures of US2.42 billion. These results highlight the urgent need to address the treatment gap and prevent fractures and counteract the associated financial burden [19].

Box 1. Areas for improvement in raising awareness of the significance of OP and decreasing its burden

\footnotetext{
A national osteoporotic fracture registry is needed (hip and major osteoporotic fractures)

Awareness should be raised and education should be provided in the diagnosis and treatment of $\mathrm{OP}$

Older male adults should be considered at risk of OP, and measures to improve the screening and treatment of OP in older males should be considered, including education

Fulfillment of the treatment gap after diagnosis is needed

A follow-up of the treatment plan is needed
}

$O P$, osteoporosis

\section{Screening and diagnostic approaches}

The diagnosis of OP in older adults is made by documenting a low-energy fragility fracture and/or $T$-scores $\leq-2.5$ derived from DXA-documented BMD identified at the femur, L1-L4, or proximal $1 / 3$ of the distal radius. As with other diseases, a focused history should be sought, and a physical examination should be performed through which the physician can assess the risk factor for $\mathrm{OP}$ and any previous or current fractures. In addition to BMD testing, imaging focusing for the identification of vertebral fractures is recommended in some subgroups in the current guidelines [7], which will ensure the determination of the severity of the disease and aid in the selection of the therapeutic approach [20].

\section{DXA scans}

The recommended age at which screening for OP should start in Turkey is 65 years in females and 70 years in males $[7,21]$, which is on the whole in line with the majority of international guidelines. It is worthy of note that in the Canadian guideline, routine DXA screening is recommended for males aged 65 years. As the prevalence of OP is high in Turkey and there is a tendency to disregard the male 
population, we suggest that it may be advisable to begin routine screening in both sexes at the age of 65 years.

For DXA evaluations, it is important for the patient to be aligned properly for optimum assessment, although to the best of our knowledge, no routine education program is implemented throughout the country. In a multicenter study by Karahan et al. from Turkey, a total of 3212 DXA scan results were collected from 20 different centers in 15 different cities in Turkey. The percentage of erroneous measurements discovered ranged from 10.5 to $65.5 \%$ in the lumbar spine, and from 21.3 to $74.2 \%$ in the proximal femur, equating to an overall error rate of $31.8 \%$ for the lumbar spine and $49.0 \%$ for the proximal femur [22]. In another study from Turkey by Tuna et al., positioning errors were detected in $64.7 \%$ of the spine X-rays, $60.5 \%$ of the hip X-rays, and $83.9 \%$ of both regions. A total of 112 (34.7\%) spinal DXA images required new $T$-score adjustments, and the $T$-scores and BMD differed between the initial reports and clinical reanalyses $(p<0.001)$ [23]. As can be understood from these findings, technicians involved in DXA scanning should undergo routine periodic education to ensure appropriate imaging in Turkey. A certification process may promote the development of a standard educational approach. Another point is the depiction of the least significant change (LSC) of each center is required while assessing response to treatment and course of BMD progress. Accordingly, all DXA centers should identify the center-specific LSC values for each technician or group of technicians and should incorporate this value in their output recordings. To the best of our knowledge, however, none of the DXA centers in the country provides specific LSC values. Also of note is the fact that the DXA scans performed in different centers and/or on different machines are not comparable. The practice of changing DXA centers is common among patients due to obstacles in the making of appointments and also due to the logistic feasibility concerns. We suggest that such a practice and nonstandard approach should be prevented at both a patient and physician level.

\section{Vertebral fracture screenings}

Vertebral fractures are mainly silent, and diagnosis may be delayed for years. When a vertebral fragility fracture is identified, an OP diagnosis is made without the need for a DXA-BMD test, and such a finding requires the initiation of treatment for OP.

Vertebral fracture screening is recommended for all older adults identified with OP and for those at high risk of fragility fracture [24]. The indications of vertebral fracture screening due to high risk for fracture are as follows: (i) females aged $>70$ and males aged $>80$ with a $T$-score of $\leq-1.0$ at the vertebra, total hip, or femoral neck; (ii) females aged 65-69 years and males aged 70-79 years with a $T$-score of $\leq-1.5$ at vertebra, total hip, or femoral neck; (iii) postmenopausal females and $\geq 50$ years males with specific risk factors for OP, including a history of low-energy trauma fractures, reduced height ( $>4 \mathrm{~cm}$ compared to peak height value), reduced height $(>2 \mathrm{~cm})$ during follow-up, and current or recent glucocorticoid treatment. Such an approach requires clinicians to access the DXA scan results and to order a vertebral fracture screening if the patient fulfills the DXA $T$-score requirement. In such cases, therefore, older adults must make repeated visits, although this will require spending substantial time (between 2 and 3 months, according to current practice in Turkey) for making and attending appointments, greater costs, and delays in diagnosis and treatment, which may be indicated by the presence of potential vertebral fractures. On the other hand, ordering vertebral $\mathrm{X}$-rays without evaluating the DXA-derived $T$-scores exposes older adults to unnecessary X-ray radiation. Considering the minimal $\mathrm{X}$-ray exposure from a single lateral dorsolumbar X-ray graphy, it may be more appropriate to order lateral dorsolumbar X-ray imaging for the screening of vertebral fractures on a routine basis at the same time as ordering a DXA scan, based on a shared decision made with the patient and/or caregiver, which is essential for the presentation of the pros and cons of the approach. This method has the potential to increase patient compliance and can be considered costeffective as it reduces the need for repeated outpatient visits, saves time, and may increase rates of OP treatment.

In practice, the most commonly used technique is direct lateral X-ray imaging of the thoracic and lumbar vertebrae, being recommended as the first-line approach [1,7]. The cheapest and safest modality in such screening is lateral vertebra DXA scanning. The imaging of all vertebrae could be performed simultaneously with DXA to screen for vertebral fractures [25]. Such imaging requires the integration of software appropriate for "vertebral fracture assessment (VFA), which is a relatively cheaper approach that is easy, practical/convenient, and safe, involving lower radiation exposure than that of direct X-ray imaging [1]. In women aged $\geq 65$ years, VFA can be considered cost-effective when incorporated into routine screening for $\mathrm{OP}$ and is referred to as an important addition to fracture risk assessment in the National Osteoporosis Foundation (NOF) guidelines [26]. A comparison between the different techniques for the detection and evaluation of vertebral fractures is presented in Table 1 [1]. To the best of our knowledge, there is no public hospital in Turkey to date that has integrated VFA software into its DXA scanning procedures.

\section{Identification of fracture risk}

BMD is important when determining fracture risk, yet it indicates the relative risk. The 10-year fracture risk can be predicted by identifying the clinical risk factors of osteoporotic fractures. The World Health Organization (WHO) recommends the use of the FRAX in this regard, and additional benefit can be drawn through the inclusion of FRACTURK data into the tool, permitting Turkey-specific risk stratification. 
Table 1 The comparison between different techniques in the detection and evaluation of vertebral fractures [1]

\begin{tabular}{llllll}
\hline Imaging method & Resolution & Radiation & Availability & Convenience & Cost \\
\hline X-ray & +++ & ++ & ++ & ++ & ++ \\
VFA & ++ & + & +++ & +++ & + \\
CT & +++ & +++ & + & + & +++ \\
MRI & +++ & 0 & + & + & +++ \\
Nuclear scan & + & ++ & + & + & +++ \\
\hline
\end{tabular}

High +++ ; medium ++ ; low + ; none 0

$V F A$, vertebral fracture asessment; $C T$, computerized tomography; $M R I$, magnetic resonance imaging
The FRAX algorithm provides a 10 -year fracture probability estimate. If the 10-year hip fracture risk is identified as $\geq 3 \%$ and/or major osteoporotic fracture risk as $\geq 20 \%$, pharmacological treatment can be considered cost-effective. The integration of FRAX scores into DXA records may promote its practical application and improve the identification of fracture risk, although to the best of our knowledge, the FRAXcalculated probability of fracture risk is not included in the DXA reports produced by public hospitals in Turkey. While FRAX may help in the decision-making process, clinicians should consider all clinical features when deciding on treatment, including, most importantly, history of falls, fall risks, diabetes, aromatase inhibitors, androgen blockade therapy, variables known to be related to fracture risk, dose-response associations with variables, the increased risk of fracture after the first fracture, other BMD site measurements, and race and ethnicity factors [27]. The consideration of all these factors needs to be promoted in Turkey.

There have been studies reporting the risk of a subsequent osteoporotic fracture to be particularly high immediately after an index fracture and to gradually decrease over time. This temporary situation, which is not currently accounted for in the FRAX algorithm, suggests that the treatment given to such patients immediately after the fracture may prevent more new fractures than later treatments. This reinforces the rationale of early intervention immediately after a fracture as a means of avoiding recurrent fractures. Quantifying the immediate risk also allows anabolic therapies to target patients who are at very high risk [28]. This approach needs to be promoted in Turkey.

The pitfalls in the screening and diagnosis of OP in Turkey are outlined in Table 2 alongside a comparison with a representative developed European country (Belgium).

\section{Osteoporosis differential diagnosis}

Osteoporosis requires a multidisciplinary approach. Secondary causes of OP (various diseases and drugs) and other metabolic bone diseases should be excluded when diagnosing primary OP. Osteomalacia is a common metabolic bone disease, especially in immobile patients and nursing home residents, and is linked to vitamin D deficiency. The prevalence of vitamin D deficiency is very high in Turkey (63\%), as is the case also in many other countries $(60 \%)[29,30]$; however, it is commonly overlooked. Measurements of $25(\mathrm{OH})$ vitamin D, alkaline phosphatase, calcium, phosphate, and the parathyroid hormone can easily aid in the differential diagnosis between osteomalacia and OP. In patients with OP, the OP-related treatment should be started only after osteomalacia has been treated [7]. Hence, due to its significant prevalence in Turkey, vitamin D deficiency should be considered a potential cause of low BMD, and its replacement should be considered before commencing treatment for OP with anti-osteoporotic medications.

Box 2. Areas for improvement in the screening, diagnosis, and identification of fracture risk

The DXA screening of males where indicated should not be ignored. The screening indication for age may be set at 65 years rather than 70 years considering the high fracture rates in Turkey

Technicians involved in DXA scanning should undergo routine periodic training to ensure appropriate imaging. A certification process may promote the adoption of a standard educational approach

All DXA centers should identify center-specific LSC values for each technician or group of technicians and should incorporate this value in their output recordings

The common practice of changing DXA centers should be prevented at both patient and physician levels

In older adults, the ordering of routine lateral dorsolumbar X-ray imaging for the screening of vertebral fractures should be considered at the same time as DXA scans through a shared decision-making approach

The integration of VFA software should be considered to allow vertebral fracture screening through a single DXA assessment

Besides DXA screening, screening using the FRAX algorithm specific to Turkey should be integrated into diagnostic practice

The FRAX score should be calculated automatically in all DXA imaging outputs and outlined in the output records

A differential diagnosis of low BMD should be made between OP and osteomalacia

Vitamin D level assessments should be considered before making an OP diagnosis

$B M D$, bone mineral density; $D X A$, dual-energy X-ray absorptiometry; $F R A X$, fracture risk assessment tool; $L S C$, least significant change; $O P$, osteoporosis; $V F A$, vertebral fracture assessment 
Table 2 The differences between Turkey and a representative European country (Belgium) in the screening, diagnosis, and treatment of OP in older adults $(>65$ years old)

\begin{tabular}{|c|c|c|}
\hline & Turkey & Belgium \\
\hline National fracture registry & Not available & Not available \\
\hline Standardized education for technicians & Not available & $\begin{array}{l}\text { Available through a course organized by the } \\
\text { Belgian Bone Club }\end{array}$ \\
\hline Identification of the center-specific LSC value & Not available & Not available \\
\hline Integration of VFA software & Not available & Available \\
\hline Fortification of foods with vitamin D & Not available & Available \\
\hline Reimbursement for anti-OP medications & Available & Available \\
\hline $\begin{array}{l}\text { The characteristics of reimbursement of } \\
\text { anti-OP medications }\end{array}$ & Reimbursement indication & \\
\hline - Oral bisphosphanates & $\begin{array}{l}\text { Low-energy (fragility) hip fracture } \\
\text { and/or }\end{array}$ & $\begin{array}{l}\text { Reimbursed when prescribed by any physician. } \\
\text { No other condition }\end{array}$ \\
\hline - Zoledronic acid & $\begin{array}{l}\text { Low-energy (fragility) fracture and } T \text {-score }<1 \\
\text { at L1-L4 or L2-L4 or total hip or femoral } \\
\text { neck }\end{array}$ & $\begin{array}{l}\text { Reimbursed if vertebral fracture or hip fracture } \\
\text { or } T \text {-scores }<-2.5 \text { at spine or total hip or } \\
\text { femoral neck }\end{array}$ \\
\hline - Denosumab & $\begin{array}{l}\text { and-scores } \leq-2.5 \text { at L1-L4 or L2-L4 or total hip } \\
\text { or femoral neck } \\
\text { and/or } \\
\text { Patient age } \geq 75 \text { years } \\
\text { and/or } \\
>5 \mathrm{mg} / \mathrm{d} \text { prednisolone use } \geq 3 \text { months and } \\
T \text {-score }<-1 \text { at L1-L4 or L2-L4 or total hip } \\
\text { or femoral neck } \\
\text { and/or } \\
\text { Rheumatoid arthritis, celiac disease, } \\
\text { inflammatory bowel disease, ankylosing } \\
\text { spondylitis, hyperthyroidism, hypogonadism, } \\
\text { hypopituitarism, anorexia nervosa, chronic } \\
\text { obstructive pulmonary disease, type } 1 \\
\text { diabetes, Cushing syndrome, primary } \\
\text { hyperparathyroidism, anticancer treatment, } \\
\text { organ transplantation, and } T \text {-score }<1 \text { at } \\
\text { L1-L4 or L2-L4, or total hip or the femoral } \\
\text { neck } \\
\text { Reimbursed only when reported by internal } \\
\text { medicine, physical therapy and rehabilitation } \\
\text { medicine, orthopedics, rheumatology, } \\
\text { endocrinology, obstetrics and gynecology, } \\
\text { medical ecology, and hydroclimatology } \\
\text { specialists } \\
\text { Denosumab can only be prescribed if the } \\
\text { patient cannot tolerate isphosphonates and/ } \\
\text { or has experienced incomplete treatment } \\
\text { response }\end{array}$ & $\begin{array}{l}\text { Reimbursed if vertebral fracture or hip fracture } \\
\text { or } \\
T \text {-scores }<-2.5 \text { at spine or total hip or the } \\
\quad \text { femoral neck } \\
\text { and } \\
\text { Previous treatment with oral BP and IV BP } \\
\text { or } \\
\text { Intolerance to BP (IV + oral) } \\
\text { or } \\
\text { Previous treatment with oral or IV BP } \\
\text { and } \\
\text { Intolerance to the other route of administration }\end{array}$ \\
\hline - Teriparatide & $\begin{array}{l}\text { A } T \text {-score } \leq-3.5 \text { at L1-L4 or total hip and the } \\
\text { presence of } \geq 2 \text { low-energy fragility fractures } \\
\text { Reimbursed only when reported by } \\
\text { geriatricians or endocrinologists } \\
\text { Maximum } 18 \text { months }\end{array}$ & $\begin{array}{l}\text { Reimbursed if previously treated for at least } \\
12 \text { months with a BP and with at least } 2 \\
\text { vertebral fractures, one of which occurred } \\
\text { during treatment for BP } \\
\text { and } \\
\text { A } T \text {-score }<-2.5 \text { at the spine, total hip, or } \\
\text { femoral neck } \\
\text { Prescription by rheumatologist, PRM, or } \\
\text { internal medicine }\end{array}$ \\
\hline Abaloparatide & Not available & Not available \\
\hline Romosozumab & Not available & Not available \\
\hline Fracture liaison services & Available in four centers & Available in four specialized centers \\
\hline Orthogeriatric approach & Available in two centers & Available in specialized centers \\
\hline
\end{tabular}




\section{Treatment of osteoporosis}

The treatment of OP in older adults is based on nonpharmacological approaches, such as aerobic exercise, like walking, and resistance exercises, as well as adequate nutrition directed at the improvement and preservation of bone mass/quality, decreasing falls, the treatment of secondary factors that cause and/or contribute to $\mathrm{OP}$, adequate daily calcium and vitamin $\mathrm{D}$ intake, and pharmacological treatments including anti-OP medications $[9,31]$.

\section{Non-pharmacological approaches}

Adequate and qualified nutrition, physical activity with patient-specific exercise programs, prevention of falls, ensuring in-home safety taking into account fall risk, education in a safe gait, the use of assistive aids for walking and mobility, hip supports/pads to decrease the impact of falls, and the cessation of smoking and limitations on alcohol intake are the main non-pharmacological approaches.

Being a common problem, nutrition is considered an essential part of OP treatment in older adults. Among older community-dwelling adults, almost $1 / 3$ suffer from undernutrition, and the prevalence is much higher (25-60\%) in nursing home residents and during hospitalization (12-50\%) [32]. In Turkey, the prevalence of undernutrition has been reported to be $30 \%$ among community-dwelling older adults [33, 34] and about $45 \%$ among nursing home residents [35]. Adequate caloric intake is essential, although nutritional quality is just as important as energy. Among the macronutrients, protein intake is of paramount importance, as inadequate protein intake has been shown to cause sarcopenia, defined as the loss of skeletal muscle mass and function. Sarcopenia has been reported in $10-40 \%$ of community-dwelling older adults [36] and in $15-70 \%$ of the residents of nursing homes $[37,38]$. There is a well-established connection between bone and muscle, osteosarcopenia, defined as the simultaneous presence of OP and sarcopenia, and it is prevalent particularly in older OP patients. Sarcopenia is a well-documented risk factor for falls, fractures, and adverse hospitalization outcomes, and so ensuring an adequate supply of protein is crucial in older OP patients in Turkey. The average protein intake has been calculated as $52.1 \mathrm{~g} /$ day in geriatric outpatients in Turkey [39], and an intake of $1.2-1.5 \mathrm{~g} / \mathrm{kg} /$ day in older adults with chronic diseases is recommended [40]. Protein intake is better to be spread throughout the day, and essential or semi-essential amino acid supplementations, such as leucine and glutamine, may be useful, especially when combined with resistance training. While a high-protein diet may increase calciuria [41], the potential harm is negligible when the benefit is considered. Other approaches to decreasing calciuria, i.e., lowering sodium intake and the use of thiazide diuretics if antihypertensive treatment is indicated, are better and more useful for its control.

Among the micronutrients, adequate calcium (1000-1200-mg elementary calcium/day) and vitamin D intake (800-1000 IU Vit D3/day) is required. If the diet is not qualified enough to make a thorough supplementation, these elements should be given as pharmacological therapies, which is discussed in the section on the pharmacological treatment of OP below.

Falls are one of the major risk factors for osteoporotic fracture and are a risk factor for fractures independent of the FRAX score $[42,43]$. Falls have been reported in around $38 \%$ of older community-dwelling adults in Turkey, while $45 \%$ have a fear of falling [44]. Falls can cause a further decrease in physical function and muscle strength [42]. Fall screening should be performed yearly in all older adults [45], and gait and balance should be assessed in older adults as they become more prevalent with age [46]. The presence of falls is an indicator of muscle weakness and/or balance problems. It has been reported that in healthy older adults, prescribed exercises of appropriate intensity and duration are effective in decreasing falls [46]. Previous studies have recommended multicomponent exercise models that combine resistance training and aerobic and proprioceptive components as an efficient means of improving balance and decreasing fall risk [47]. Balance training, for example, through Tai-chi, has been suggested worldwide to counter increased fall risk, although this falls outside the cultural boundaries of older Turkish people. For this reason, balance exercises that are applicable to this demographic that have greater potential for compliance should be promoted.

To improve/preserve bone mass, muscle mass, and strength, aerobic exercises like walking and resistance training are recommended [48, 49], and while exercise may be challenging for older people with vertebral fractures, it is very much needed. Supervised exercises focused on strengthening the back extensors have been shown to be superior to the home program exercise in terms of improving pain, muscle strength, endurance, mobility, and quality of life [50]. In those suffering from hip fractures, progressive knee extensor strengthening exercises have been shown to improve functional outcomes when started in the postoperative third week [48]. In Turkey, however, physical activities are limited among older adults, in which there is no sports center culture, and so there is a national need to promote increased and improved physical activity. In this context, older adults, including those with health limitations, can be provided both social play and competitive appropriate opportunities in an informal and more social sport environment by the government. In this regard, they may be encouraged to take part in individual sports or organized activities, such as physical activity classes. This 
could encourage older adults to consider sportive activities not only as sport, but also as an attractive means of staying physically active, enjoying themselves, engaging in social networking, developing friendships, maintaining physical fitness, and improving their self-image.

Spinal orthosis applications are also important in vertebral fractures, and there have been reports suggesting the use of spinal orthoses for 3 months for the control of pain and strengthening the extensor back muscles [51, 52]. Thermotherapy, transcutaneous electrical nerve stimulation (TENS), positioning, and mild exercise are all considered to control pain after a fracture $[48,53]$, although these modalities are limited in Turkey in most settings.

\section{Pharmacological approaches}

For an effective OP treatment with anti-OP medications, clinicians should consider polypharmacy and compliance $[53,54]$. It is well known that adherence to OP drugs is poor and inadequate, ranging from 34 to $75 \%$ in the first year of treatment, while persistence levels at 1 year are estimated to be in the range of $18-75 \%$. This poor adherence rate leads to an increased fracture rate (up to $30 \%$ ), worse health outcomes (more subsequent fractures, lower quality of life, and higher mortality), and impaired cost-effectiveness [55].

\section{Vitamin D and calcium}

The basis of OP treatment is the adequate provision of vitamin D and calcium. Vitamin D is crucial for the sustainment of calcium absorption, bone health, muscle performance, and decreased fall risk and has been suggested to have numerous extraskeletal effects, as almost all cells in the body contain vitamin $\mathrm{D}$ receptors. The recommended serum level for $25(\mathrm{OH})$ Vit D3 is $\geq 30 \mathrm{ng} /$ $\mathrm{mL}(50 \mathrm{nmol} / \mathrm{L})$, and while levels of around $50 \mathrm{ng} / \mathrm{mL}$ are acceptable, $>100 \mathrm{ng} / \mathrm{mL}$ should be avoided [7]. The recommended vitamin D intake is $800-1000$ IU D3/day; however, resources of vitamin D through nutrition are limited in many countries. The primary route is through the skin; however, vitamin D synthesis in the skin is decreased in older adults, and many older people go out only occasionally or rarely, limiting skin synthesis. Furthermore, vitamin D receptors in the gut are reduced in older adults, thereby decreasing the effect. Dietary elements rich in vitamin D are limited to few sources, such as fish and giblets, and so some dairy products are systematically, mandatorily, or voluntarily fortified with vitamin $D$ in a number of developed countries where there is a high quality of life, an improved economy, and an advanced technological infrastructure, such as Belgium, Finland, Norway, Sweden, Canada, and the USA. In other countries, such as the UK, Ireland, Spain, and Australia, supplementation is not systematic, although a number of vitamin D-fortified dairy products are available [56]. In Turkey, vitamin D deficiency (66\%) and insufficiency (24\%) are common among older adults [7], and so, vitamin D fortifications aimed at overcoming the deleterious effects of vitamin $\mathrm{D}$ deficiency are required [9, 57].

When vitamin D deficiency is identified, cholecalciferol (Vit D3) is preferred over ergocalciferol (Vit D2) due to its more efficient increase of serum $25(\mathrm{OH})$ Vit D3 levels. In cases of vitamin D deficiency, vitamin D3 is recommended to be given at 50,000 IU/week for 8 weeks as a loading dose and then continued with 800-2000 IU/day as maintenance therapy [58]. The optimal intake is $800-1000$ IU daily, which can be upped to the tolerable limit of vitamin $\mathrm{D}$, i.e., $4000 \mathrm{IU} /$ day $[54,59]$. It should be noted that vitamin D should not be given periodically in high doses (300,000 IU) as it provides no additional benefit but may increase the risk of falls [60]. In a randomized controlled trial, the effects of several daily vitamin $\mathrm{D}$ doses on falls were examined in postmenopausal women with baseline serum $25(\mathrm{OH})$ vitamin D levels of $\leq 20 \mathrm{ng} / \mathrm{mL}$. The participants were asked to provide a $1200-1400 \mathrm{mg} /$ day of calcium intake, and if they could not increase their dietary calcium intake to those levels, a calcium product (mean, $580 \mathrm{mg}$ ) was given. The rates of falls at high doses of vitamin D - of 4000 and $4800 \mathrm{IU} /$ day - were higher than at doses of 1600-3200 IU/ day. Accordingly, it can be understood that in older women, especially those with a history of falls, the safe upper limit for vitamin D may be narrower than previously described [61] With this in mind, <4000 IU/day supplementation may be a better replacement choice, although the general principle of "start low-go slow" should be considered in older adults. It is thus suggested that vitamin D replacement be carried out gradually [54]. As a formerly standard approach in clinical practice, the prescription of high doses of vitamin $\mathrm{D}$, such as 300,000 IU, is still common in some physicians, which is most likely attributable to a lack of education and limited knowledge of recent reports on the potential adverse effects of high-dose administrations of vitamin D. As such, we draw attention to the fact that prescribing high doses of vitamin D should be avoided. The postgraduate education of physicians can have the potential to mitigate this problem. Vitamin D prescriptions are reimbursed by social security institutions, and so the problem is not financial in most cases.

Calcium intake is of utmost importance in the treatment of OP. Males aged 50-70 are recommended to take $1000 \mathrm{mg} /$ day, while females aged $>50$ years and males aged $>70$ have a recommended calcium intake of $1200 \mathrm{mg} /$ day $[7,9]$. The intake of calcium is recommended through adequate nutrition, as there have been studies suggesting an association between adverse cardiovascular events and calcium supplementation as a pharmacological therapy, and this issue is yet to be resolved $[62,63]$. Uncertainty remains 
about the cardiovascular risk of high daily calcium intake (more than 1200-1500 mg daily), and non-dietary high calcium intake may result in hypercalcemia, hypercalciuria, and urolithiasis, all of which can be devastating in older adults, and as higher intakes have no proven skeletal benefit, excessive calcium intake (more than 1200-1500 mg daily) should be avoided [7, 62]. If the dietary calcium intake is lower than $800 \mathrm{mg}$, supplements are advised, although supplements that contain $>500 \mathrm{mg}$ of elemental calcium are not recommended at any one time. The dietary elements that are rich in calcium are milk, dairy products, green leafy vegetables, hazelnut, soy products, and fruit juices, although for older adults at risk of malnutrition, diet alone may not be adequate. In Turkey, supplements can be found to contain calcium carbonate and calcium citrate. While carbonate salt is cheaper, calcium absorption is lower during the fasting state and the coadministration of proton pump inhibitors and $\mathrm{H} 2$ receptor blockers. Clinicians should consider the fact that caffeine, mineral water, and $>2 \mathrm{~g} / \mathrm{kg} /$ day protein intake has the potential to decrease calcium absorption and/or calciuria. In Turkey, inquiries of adequate calcium intake, especially in older adults, are often overlooked. Insufficient calcium intake among older adults is a global problem [64], and we believe that the calcium intake also in Turkey is significantly lacking. According to our evaluation of the records of the geriatric outpatient clinics in which we provide care to community-dwelling older adults with a wide range of functionality (from total dependency to total independency), the average calcium intake was found to be $715.6 \mathrm{mg} /$ day [39]. This is again attributable to the lack of awareness of this global and nationwide problem. Both the postgraduate education provided to healthcare providers and activities aimed at educating the public can support the resolution of this problem. We aim to highlight that older adults should endeavor to consume enough dietary calcium (1000-1200 mg) per day. In cases where older adults cannot meet their needs through diet, supplementary calcium should be prescribed, and as medications containing calcium are reimbursed, financial issues tend not to be a hurdle.

\section{Anti-osteoporotic medications}

Fracture risk and co-morbidities should be considered when organizing the pharmacological treatment of OP in older adults, and the preferences of the patient as regards drug intake routes and intervals (weekly, monthly, yearly) should also be considered. Of note, a basal requirement before starting all anti-OP medications is ensuring adequate levels of vitamin $\mathrm{D}$ and daily vitamin $\mathrm{D}+$ calcium intake.

The documentation of OP by BMD or fragility fractures [7] should prompt the initiation of anti-OP medications, provided that vitamin $\mathrm{D}$ and calcium supply are adequate. If the 10-year probability of fracture risk is higher than the treatment thresholds (hip fracture $\geq 3 \%$ and/or major OP fracture $\geq 20 \%$ ), anti-OP medications should also be commenced. In Turkey, however, while the presence of fragility hip fractures is adequate for the reimbursement of anti-OP drugs, other fragility fractures should be accompanied by osteopenia for such reimbursements. This approach is problematic, as false high BMD scores are frequently present in older adults due to degenerative vertebral changes, and can be due to vertebral fractures if present. Although the patient is actually osteoporotic, OP may not be apparent and so the necessary anti-OP treatment may be delayed. In such cases, the affected vertebrae should be excluded from the DXA analysis and the mean BMD should be calculated from the remaining vertebrae [65]. That said, anti-osteoporotic medications are not reimbursed in such cases in Turkey. We suggest that in cases in which some vertebrae are to be excluded from the analysis, reimbursements should be made if any two vertebrae $T$-scores are lower than -2.5 .

Regarding the choice and duration of specific anti-OP medications, most guidelines suggest that OP treatment choices should be made according to the fracture risk [66-68]. The first drug of choice is generally anti-resorptive, unless there is a very high-risk situation and a high imminent fracture risk. Bisphosphonates, i.e., alendronate, risedronate, zoledronate, or denosumab, may be started, and if vertebra-specific OP treatment is needed, ibandronate may also be an option. In cases who are intolerant to oral bisphosphonates, zoledronate or denosumab may both be reasonable first-line options. The risk of the fracture determines treatment duration. In cases of moderate fracture risk, oral bisphosphonates should be limited to 5 years and zoledronate to 3 years. Previous studies have reported that oral bisphosphonate treatments can be continued for up to 10 years $[69,70]$ and zoledronate for up to 6 years without a treatment interval $[68,71]$ if the fracture risk is determined high, although a 2-year treatment holiday should be introduced afterward. An anabolic agent followed by antiresorptive is recommended in very high-risk patients, while anti-resorptives are considered more suitable for high-risk patients [72], and this approach should be popularized in Turkey.

Furthermore, cases of BMD loss higher than centerspecific LSC levels and/or the occurrence of fractures should be followed up. If the fracture risk is determined high, oral bisphosphonate treatments can be given for 10 years and zoledronate for 6 years without a treatment interval. Denosumab has been shown to be a safe option for 10 years [73]. If the patient has received long-term oral bisphosphonates, zoledronate, or denosumab and still has a high fracture risk, anabolic treatments (teriparatide, abaloparatide, romosozumab) may be given. Treatment durations with an anabolic agent are limited to 12 months for romosozumab and 24 months for teriparatide and 
abaloparatide, the efficacy of which will decrease after the treatment is stopped, and so anti-resorptive treatments should be introduced consecutively after anabolic agents [72]. In Turkey, such sequential treatment models should be routinized, and certainly not ignored. Anti-osteoporosis drugs have been associated with potential increased cardiac risk (calcium supplementation, romosozumab), no effect on cardiac risk (vitamin D), or reduced cardiac risk (bisphosphonates). Romosozumab has been shown to have possible cardiovascular side effects (myocardial infarction, stroke, and cardiovascular death). Bisphosphonates could theoretically protect against atheroma by improving arterial elasticity, reducing systemic vascular resistance and carotid artery intima-media thickness, inhibiting the mevalonate pathway and intravascular calcification, and reducing the circulating $\gamma \delta \mathrm{T}$ cells that stimulate atherosclerotic progression. Data from randomized and observational studies, however, have neither strongly supported this nor consistently demonstrated a potential association with atrial fibrillation [62]. Drugs with a risk of cardiac side effects in particular should be used with caution.

Considering the heavy economic burden of osteoporotic fractures and limited health resources, the cost-effectiveness of anti-osteoporotic drugs has gained importance. In a systematic review in 2020, potent anti-osteoporotic agents (such as denosumab, zoledronic acid, and teriparatide) were generally reported to be more cost-effective than oral bisphosphonates, while sequential therapy had the potential to produce additional health benefits and be more costeffective than monotherapy [74].

Reimbursements for anti-OP medications from the social security system are possible in Turkey, which is a considerable advantage of the Turkish health system, affordability being an important factor that prevents the adherence of patients to anti-OP treatment. That said, OP is not considered a chronic disease, meaning that patients are not totally exempt from payment, leading to some compliance problems, as this is a chronic disease requiring long-term sustained therapy.

The underuse of anti-osteoporotic medications is a common global problem $[75,76]$ due both to the ignorance in evaluating $\mathrm{OP}$ as a part of routine screening for primary prevention and due to ignorance of secondary prevention approaches following a fragility fracture. This ignorance is a frequently encountered problem, even in those suffering from hip fractures [77]. Problems may arise due to lack of education and/or lack of engagement with OP by physicians, and this situation is found also in Turkey [9]. A lack of coordination in healthcare systems may also be a factor; as in some cases, physicians do not fail to advise patients to seek medical treatment for OP, but patients may fail to administer to an OP center. These problems can again be attributed to a lack of awareness, and also to problems in the patient-physician relationship, being areas in need of improvement, potentially through public education programs to the training of health professionals.

Bisphosphonates (alendronate, risedronate, ibandronate, zoledronate) are the most commonly used and most preferred agents, although there are concerns regarding their long-term use. They can be given orally or intravenously (IV). Renal failure is frequent in aging and should be considered as the elimination route is via the kidneys. Zoledronate and alendronate should not be given if the estimated glomerular filtration rate (eGFR) is $<35 \mathrm{~mL} / \mathrm{min} / 1.73 \mathrm{~m}^{2}$, and other bisphosphonates should not be given if eGFR is $<30 \mathrm{~mL} / \mathrm{min} / 1.73$ $\mathrm{m}^{2}$ [54]. The transfusion rate of IV bisphosphonates has an adverse effect on renal functions. The most common side effects of oral agents are upper gastrointestinal problems and muscle aches and post-injection flu-like syndrome with IV agents. In those using for more than 5 years, atypical femur fractures and jaw osteonecrosis are a concern, and dental problems should be managed before treatment is commenced. As dental problems are common in older adults, dentists may consider tooth extractions. While there have been reports recommending routine dental examinations before the initiation of bisphosphonates [78, 79], others have claimed that they are unnecessary $[80,81]$, suggesting that such an approach may delay the initiation of treatment. On the other hand, if an older patient spontaneously suggests dental problems with screening by questioning, they should be referred for a dental evaluation before treatment initiation [81]. Tooth extractions should be avoided if not vital, as tooth loss is significantly associated with the development of malnutrition, which can have devastating consequences in older adults [82-84].

Denosumab is the first biological agent to be introduced for the treatment of OP, being a monoclonal antibody that acts by inhibiting osteoclasts. In contrast to bisphosphonates, it is not stored or accumulated in bony tissue, and therefore, despite being a potent anti-resorptive agent, its effect reverses after 6 months of a single dose, and bone turnover begins to rise abruptly, and 2 years after treatment cessation, BMD returns to the pre-treatment values. In a recent study involving 1001 participants who received at least two doses of denosumab, the rate of vertebral fracture was reported to be six times higher in cases in which denosumab treatment was stopped within at least 7 months of follow-up. It was thus concluded that the time between two doses of denosumab should not exceed 6-8 months, especially in those who received $\geq 2$ doses of denosumab. Similarly, sequential bisphosphonate therapy should be introduced within 6-8 months of the last dose of denosumab [85]. Therefore, continuous denosumab treatment, or denosumab treatment followed by bisphosphonates after cessation, should be considered. Hypocalcemia is a considerable risk due to its potent anti-resorptive action and may be especially prevalent in older adults if adequate calcium and vitamin D intake is not 
ensured. The risk of atypical femur fracture and osteonecrosis of the jaw is less for denosumab compared to bisphosphonates. Another important advantage over bisphosphonates is that denosumab is not nephrotoxic and can be given at any eGFR level if treatment for OP is indicated [86]. That said, the risk of hypocalcemia is highest in cases of advanced renal failure and may be a significant problem that requires monitoring. The problem of denosumab in Turkey is that some older adults do not comply with the approach to be rigorous on receiving denosumab at the end of 6 months, at which time its effect dissipates. This problem is more prevalent among those of lower socioeconomic status and has also been linked to problems in the patient-physician relationship. Denosumab, on the other hand, is reimbursed in its all approved indications, which is an advantage in the country in terms of OP treatment.

Teriparatide, a recombinant parathyroid analog, is the only anabolic agent currently available in Turkey. It is contraindicated in cases of hyperparathyroidism, metabolic bone diseases such as hypermetabolic bone disease, unexplained increased parathyroid hormone (PTH), bone metastases, radiotherapy applied to the bone, and severe renal failure. The mild and transient side effects include nausea, orthostatic hypotension, and leg cramps. Treatment should be restricted to 24 months. In patients suffering from pain related to fragility fractures, teriparatide has the advantage of controlling pain and effectively treating the OP. In Turkey, teriparatide is reimbursed by social security institutions, as with the other anti-OP treatment options, although the reimbursement terms for teriparatide are limited to a $T$-score of $\leq-3.5$ and the presence of $\geq 2$ fragility fractures. The benefit of teriparatide is believed to be greatest when given as a first-line agent in high-risk patients [87, 88]. Therefore, it could be wise to introduce teriparatide earlier in the treatment course despite the common practice of its use after failure of anti-resorptive therapies. Widening reimbursement practices has the potential of benefit while combating OP and its consequences. Another point worth noting is that in Turkey, teriparatide is reimbursed only when prescribed by endocrinologists and geriatricians. Different to other countries, physical medicine and rehabilitation (PMR) specialists see a large number of OP patients, and OP is a component of their specialists' training programs [19]. We suggest that PMR specialists working in tertiary centers shall be allowed to prescribe reimbursed teriparatide, provided that followups for teriparatide treatments are performed effectively in terms of the potential hormonal side effects. Teriparatide treatment should be followed by anti-resorptive therapies (bisphosphonates or denosumab in older adults) to ensure its ongoing benefit [87].

Abaloparatide is an anabolic agent that selectively activates the parathyroid hormone 1 (PTH1) receptor signaling pathway and stimulates bone formation. It is used in postmenopausal women with $\mathrm{OP}$ who are at high risk of fracture or in whom other OP treatments have failed or were not tolerated. Clinical evidence suggests that abaloparatide may reduce the risk of new vertebral and non-vertebral fractures and increase BMD. There is also less risk of hypercalcemia than with teriparatide $[89,90]$. The availability and reimbursement of abaloparatide have the potential to improve the management of OP in the country.

Romosozumab is a humanized monoclonal antibody that promotes bone formation and inhibits bone resorption by inhibiting sclerostin and expands the treatment options in men and postmenopausal women who are at high osteoporotic fracture risk and in those who fail or do not tolerate other existing OP treatments. It has been reported to reduce the risk of vertebral and clinical fractures and increase BMD in women with postmenopausal OP. It is contraindicated in those with a history of myocardial infarction or ischemic stroke but has a manageable tolerability profile $[91,92]$. The availability and reimbursement of romosozumab have the potential to improve the management of OP in the country.

It should be noted that while anti-resorptive agents are considered the first-line background treatment for patients at low or medium risk of OP, those at very high risk should be treated from the outset, with a bone-forming agent. Sequential treatments are extremely important, i.e., anabolic agents followed by anti-resorptive agents or bone-forming agents following anti-resorptive agent treatments if the effect is not deemed sufficient. It should be reminded that treatment for OP is a long-term process and that innocuity on the bone and all body systems, including cardiovascular safety, is of critical importance.

The lack of adherence to anti-osteoporosis treatment is one of the major factors decreasing the efficacy of antiosteoporosis medications. An attempt to identify how, and for what duration, patients take their drugs would be a considerable asset.

\section{Fracture liaison services}

Fracture liaison services (FLSs) aim to initiate OP treatment and provide the best possible patient care, aiming to prevent falls and secondary fractures, especially those of the hip [91]. This method is beneficial and cost-effective and is currently a major determinant of any strategy's success, aiming to close the OP treatment gap. In this regard, establishing these services is of utmost importance in the early diagnosis and treatment of falls, fracture development, and OP [93, 94]. Fracture recency is one of the most important factors when assessing fracture probability. In our country, FLSs are available only at Cerrahpaşa Medical Faculty Hospital, Fatih Sultan Mehmet Training and Research Hospital, Ankara City Hospital, and 
Medicana International Ankara Hospital [95]. A larger number of qualified FLSs need to be established as a matter of urgency.

The reasons why FLSs are available in only a few centers in Turkey are numerous. First, an FLS requires a dedicated coordinator — often a well-educated nurse — who works under the supervision of a specialist physician and takes care of all aspects of the process (identification, investigation, and intervention with therapy). Hence, personnel who can be fully dedicated to FLS are needed; however, resources seem to be limited in most centers. In addition, certification and education in the initiation and implementation of FLS, provided by the National Osteoporosis Foundation (NOF), would be ideal for the establishment of an FLS, which again demands resources that may be limited in most centers. Another factor underlying the limited number of FLS seems to be a lack of education and awareness on the importance of secondary prevention in those that have experienced a recent fracture. It is worthy of note that many patients, despite having sustained a fracture, may be unaware that they have OP [96]. In this regard, education in understanding the need for FLSs at a physician and patient level, and increasing the availability of resources for their establishment, will have the potential to increase the number of FLSs. The FLS model has been linked to a reduction in re-fracture risk and reduced mortality and is considered a cost-effective approach [97].

\section{Orthogeriatrics}

Orthogeriatrics is a multidisciplinary team approach that aims to make adequate and timely interventions in individuals suffering from fragility fractures, especially those of the hip. The orthogeriatric approach aims to restore functionality as soon as possible and to reduce disability and mortality through the implementation of optimal treatment, rehabilitation, and the secondary prevention of further falls and fractures. This model has been shown to have the shortest time to surgery, the shortest length of inpatient stay, and the lowest inpatient mortality rate and so should be considered an important means of improving the treatment of fragility fractures. While several developed countries have established orthogeriatric services to date, many others have not. Centers in Turkey that apply the orthogeriatric care concept are limited in number, with the first comprehensive orthogeriatric care concept in Turkey being established in our faculty — the Istanbul University Faculty of Medicine, followed by Istanbul Prof. Dr. Cemil Taşçığlu City Hospital [98]. Similar to FLS, the limited application of the orthogeriatric approach in Turkey can be linked to a lack of education, awareness, and resources and the limited number of geriatricians in the country [99].

In Table 2, we provide an outline of the pitfalls in the treatment of OP in Turkey, alongside a comparison with a representative developed European country (Belgium).

Box 3. Areas for improvement in the treatment of OP

Adequate and qualified nutrition, and the adequate provision of protein, vitamin $\mathrm{D}$, and calcium, should be supplied at the population level

Lifestyle changes considering the cultural background of Turkish people should be promoted

Fortification of foods with vitamin D is required

Prescribing high doses of vitamin D should be avoided

OP should be regarded as a "chronic disease," thereby making it exempt from contributory fee payments and thus increasing treatment compliance

Education of the public and health professionals can make improvement for the underuse of anti-osteoporotic medications

The presence of a fragility fracture should be sufficient for the reimbursement of anti-OP medications

The identification of high-fracture risk through a country-specific FRAX algorithm should be integrated into reimbursement terms

Reimbursement should be provided if any two vertebra $T$-scores are lower than -2.5

The presence of falls and high fall risk should be integrated into reimbursement terms

The importance of compliance with timely denosumab injections should not be ignored

A widening of teriparatide reimbursements should be considered (up to 24 months rather than the current 18 months, and in less severe cases than those in the current terms). For example, the presence of Genant stage 2 or 3 vertebral fracture or the presence of a $T$-score of $\leq-3.5$, regardless of the presence of a fragility fracture

The availability and reimbursement of abaloparatide and romosozumab should be provided

Attempts to improve in what ways and for how long patients take their drugs are required to be implemented

A higher number of "fracture liaison services" should be established for the follow-up of patients with fragility fractures

$F R A X$, fracture risk assessment; $O P$, osteoporosis

\section{Conclusion}

The management of OP in older adults involves different stages, including screening, diagnostic steps, and treatment. The present study has provided an outline of the current situation regarding OP in older adults in Turkey, and identified areas in need of improvement, and has made a clear call for action to address the areas of possible improvement. The practical consideration of these suggestions has great potential in the struggle against the adverse consequences of OP in society. This approach can be modeled for other populations to improve the global management of OP. 
Author contribution Bahat G, Catikkas NM, Yavuz DG, Borman P, Guzel R, and Reginster JY contributed to the study. Bahat G and Catikkas NM contributed to the study design. Bahat G, Catikkas NM, Yavuz DG, Borman P, and Guzel R conducted the literature review. Bahat G and Reginster JY carried out the critical review. All the co-authors read and approved the final version of the manuscript.

Availability of data and materials Data are available from the corresponding author upon reasonable request.

\section{Code availability N/A.}

\section{Declarations}

Conflicts of interest Gulistan Bahat has received a speaker honorarium from Company LILLY and Company AMGEN. Nezahat Muge Catikkas has no conflicts of interest to declare that are relevant to the content of this article. Dilek Gogas Yavuz has no conflicts of interest to declare that are relevant to the content of this article. Pinar Borman has no conflicts of interest to declare that are relevant to the content of this article. Rengin Guzel has received a speaker honorarium from Company Lilly, Company Amgen, and Company Novartis. Jean Yves Reginster has received consulting fees and has served on the paid advisory boards of the following companies: IBSA-Genevrier, Mylan, Radius Health, Pierre Fabre, Faes Farma, Rejuvenate Biomed, Samumed, Teva, Theramex, Pfizer, Mithra Pharmaceuticals. He has received lecture fees for speaking upon the invitation of sponsors from the following companies: IBSA-Genevrier, Mylan, CNIEL, Dairy Research Council (DRC), Nutricia, Danone, AgNovos. He has also benefited from grant support from the following companies (institutional): IBSA-Genevrier, Mylan, CNIEL, Radius Health, TRB.

\section{References}

1. IOF. Access date September 22, 2021. https://www.osteoporosis. foundation/health-professionals/fragilityfractures/epidemiology

2. Ensrud KE (2013) Epidemiology of fracture risk with advancing age. J Gerontol A Biol Sci Med Sci 68(10):1236-1242. https:// doi.org/10.1093/gerona/glt092

3. Tuzun S, Eskiyurt N, Akarirmak U, Saridogan M, Senocak M, Johansson H, Kanis JA, Turkish Osteoporosis Society (2012) Incidence of hip fracture and prevalence of osteoporosis in Turkey: the FRACTURK study. Osteoporos Int. 23(3):949-55. https://doi. org/10.1007/s00198-011-1655-5

4. Cauley JA, Thompson DE, Ensrud KC, Scott JC, Black D (2000) Risk of mortality following clinical fractures. Osteoporos Int 11(7):556-561. https://doi.org/10.1007/s001980070075

5. Rizkallah M, Bachour F, Khoury ME, Sebaaly A, Finianos B, Hage RE, Maalouf G (2020) Comparison of morbidity and mortality of hip and vertebral fragility fractures: which one has the highest burden? Osteoporos Sarcopenia. 6(3):146-150. https:// doi.org/10.1016/j.afos.2020.07.002

6. Gurger M (2019) Factors impacting 1-year mortality after hip fractures in elderly patients: a retrospective clinical study. Niger J Clin Pract 22(5):648-651. https://doi.org/10.4103/njcp.njcp_327 18

7. Türkiye Endokrinoloji ve Metabolizma Derneği Osteoporoz ve Metabolik Kemik Hastalıkları Tanı ve Tedavi Kılavuzu. Bayt Bilimsel Araştırmalar Basın Yayın ve Tanıtım Ltd. Sti. Baskı Tarihi: Kasım 2020. ISBN: 987-605-4011-41-4

8. Beaudart $\mathrm{C}$, Biver $\mathrm{E}$, Bruyère $\mathrm{O}$, Cooper $\mathrm{C}$, Al-Daghri $\mathrm{N}$, Reginster JY, Rizzoli R (2018) Quality of life assessment in musculo-skeletal health. Aging Clin Exp Res 30(5):413-418. https://doi.org/10.1007/s40520-017-0794-8

9. Kirazlı Y, Atamaz Çalış F, El Ö, Kutsal YG, Peker Ö, Sindel D, Tuzun Ş, Gogas Yavuz D, Durmaz B, Akarirmak Ü, Bodur H, Hamuryudan V, Inceboz U, Öncel S (2020) Updated approach for the management of osteoporosis in Turkey: a consensus report. Arch Osteoporos 15(1):137. https://doi.org/10.1007/ s11657-020-00799-0

10. Aziziyeh R, Amin M, Habib M, Garcia Perlaza J, Szafranski K, McTavish RK, Disher T, Lüdke A, Cameron C (2019) The burden of osteoporosis in four Latin American countries: Brazil, Mexico, Colombia, and Argentina. J Med Econ 22(7):638-644. https://doi. org/10.1080/13696998.2019.1590843

11. Berry SD, Kiel DP, Colón-Emeric C (2019) Hip fractures in older adults in 2019. JAMA 321(22):2233-2234

12. Kanis JA, Odén A, McCloskey EV, Johansson H, Wahl DA, Cooper C, IOF Working Group on Epidemiology and Quality of Life (2012) A systematic review of hip fracture incidence and probability of fracture worldwide. Osteoporos Int 23(9):2239-56. https://doi.org/10.1007/s00198-012-1964-3

13. Kutsal YG, Atalay A, Arslan S, Başaran A, Cantürk F, Cindaş A, Eryavuz M, Irdesel J, Karadavut KI, Kirazli Y, Sindel D, Senel K, Güler-Uysal F, Yildirim K (2005) Awareness of osteoporotic patients. Osteoporos Int 16(2):128-133. https://doi.org/10.1007/ s00198-004-1678-2

14. Keskin Y, Cekin MD, Gunduz H, Luleci NE, Giray E, Sur H, Akyuz G (2014) The prevalence of osteoporosis in the Thrace region of Turkey: a community-based study. Turk J Phys Med Rehab 60(4):335-340

15. Kucukler FK, Simsek Y, Turk AÇ, Arduc A, Guler S (2017) Osteoporosis and silent vertebral fractures in nursing home resident elderly men in Turkey. J Clin Densitom 20(2):188-195. https:// doi.org/10.1016/j.jocd.2015.05.064

16. Kilci O, Un C, Sacan O, Gamli M, Baskan S, Baydar M, Ozkurt B (2016) Postoperative mortality after hip fracture surgery: a 3 years follow up. PLoS ONE 11(10):e0162097. https://doi.org/10. 1371/journal.pone.0162097

17. Tanriover MD, Oz SG, Tanriover A, Kilicarslan A, Turkmen E, Guven GS, Saracbasi O, Tokgozoglu M, Sozen T (2010) Hip fractures in a developing country: osteoporosis frequency, predisposing factors and treatment costs. Arch Gerontol Geriatr 50(3):e138. https://doi.org/10.1016/j.archger.2009.04.010

18. Cobden A, Cobden SB, Camurcu Y, Ucpunar H, Duman S, Sofu H (2019) Effects of postoperative osteoporosis treatment on subsequent fracture and the 5-year survival rates after hemiarthroplasty for hip fracture. Arch Osteoporos 14(1):100. https://doi.org/10. 1007/s11657-019-0657-3

19. Aziziyeh R, Garcia Perlaza J, Saleem N, Kirazlı Y, Akalın E, McTavish RK, Duperrouzel C, Cameron C (2020) The burden of osteoporosis in Turkey: a scorecard and economic model. Arch Osteoporos 15(1):128. https://doi.org/10.1007/ s11657-020-00801-9

20. Kendler DL, Bauer DC, Davison KS, Dian L, Hanley DA, Harris ST, McClung MR, Miller PD, Schousboe JT, Yuen CK, Lewiecki EM (2016) Vertebral fractures: clinical importance and management. Am J Med 129(2):221.e1-10. https://doi.org/10.1016/j. amjmed.2015.09.020

21. Shuhart CR, Yeap SS, Anderson PA, Jankowski LG, Lewiecki EM, Morse LR, Rosen HN, Weber DR, Zemel BS, Shepherd JA (2019) Executive summary of the 2019 ISCD position development conference on monitoring treatment, DXA cross-calibration and least significant change, spinal cord injury, peri-prosthetic and orthopedic bone health, transgender medicine, and pediatrics. J Clin Densitom 22(4):453-471. https://doi.org/10.1016/j.jocd. 2019.07.001 
22. Karahan AY, Kaya B, Kuran B, Altındag O, Yildirim P, Dogan SC, Basaran A, Salbas E, Altınbilek T, Guler T, Tolu S, Hasbek Z, Ordahan B, Kaydok E, Yucel U, Yesilyurt S, Polat AD, Cubukcu M, Nas O, Sarp U, Yasar O, Kucuksarac S, Turkoglu G, Karadag A, Bagcaci S, Erol K, Guler E, Tuna S, Yildirim A, Karpuz S (2016) Common mistakes in the dual-energy X-ray absorptiometry (DXA) in Turkey. A retrospective descriptive multicenter study. Acta Medica (Hradec Kralove) 59(4):117-123. https://doi. org/10.14712/18059694.2017.38

23. Tuna F, Yavuz S, Demirbağ Kabayel DD, Sarıkaya A (2017) Effects of clinical reanalysis in dual energy X-ray absorptiometry reports. Turk J Phys Med Rehabil 63(3):201-206. https://doi.org/ 10.5606/tftrd.2017.595

24. Cosman F, de Beur SJ, LeBoff MS, Lewiecki EM, Tanner B, Randall S, Lindsay R, National Osteoporosis Foundation (2014) Clinician's guide to prevention and treatment of osteoporosis. Osteoporos Int 25(10):2359-81. https://doi.org/10.1007/ s00198-014-2794-2

25. Lenchik L, Rogers LF, Delmas PD, Genant HK (2004) Diagnosis of osteoporotic vertebral fractures: importance of recognition and description by radiologists. AJR Am J Roentgenol 183(4):949_ 958. https://doi.org/10.2214/ajr.183.4.1830949

26. Yang J, Cosman F, Stone PW, Li M, Nieves JW (2020) Vertebral fracture assessment (VFA) for osteoporosis screening in US postmenopausal women: is it cost-effective? Osteoporos Int 31(12):2321-2335. https://doi.org/10.1007/s00198-020-05588-6

27. Kanis JA, McCloskey EV, Johansson H, Strom O, Borgstrom F, Oden A, National Osteoporosis Guideline Group (2008) Case finding for the management of osteoporosis with FRAX--assessment and intervention thresholds for the UK. Osteoporos Int 19(10):1395-1408. https://doi.org/10.1007/s00198-008-0712-1. Erratum in: Osteoporos Int. 2009;20(3):499-502

28. Kanis JA, Johansson H, Harvey NC, Gudnason V, Sigurdsson G, Siggeirsdottir K, Lorentzon M, Liu E, Vandenput L, McCloskey EV (2020) Adjusting conventional FRAX estimates of fracture probability according to the recency of sentinel fractures. Osteoporos Int 31(10):1817-1828. https://doi.org/10.1007/ s00198-020-05517-7

29. Alpdemir M, Alpdemir MF (2019) Vitamin D deficiency status in Turkey: a meta-analysis. Int J Med Biochem 2(3):118-131. https:// doi.org/10.14744/ijmb.2019.04127

30. Holick MF (2017) The vitamin D deficiency pandemic: approaches for diagnosis, treatment and prevention. Rev Endocr Metab Disord 18(2):153-165. https://doi.org/10.1007/s11154-017-9424-1

31. Russo CR (2009) The effects of exercise on bone. Basic concepts and implications for the prevention of fractures. Clin Cases Miner Bone Metab 6(3):223-8

32. Wallace JI (2017) Malnutrition and enteral/parenteral alimentation, Hazzard's Geriatric Medicine and Gerontology. Chapter 35, 7th edn. The McGraw-Hill Companies, New York, p 737

33. Bahat G, Tufan F, Bahat Z, Aydin Y, Tufan A, Akpinar TS, Erten N, Karan MA (2013) Assessments of functional status, comorbidities, polypharmacy, nutritional status and sarcopenia in Turkish community-dwelling male elderly. Aging Male 16(2):67-72. https://doi.org/10.3109/13685538.2013.771329

34. Bahat G, Tufan A, Aydin Y, Tufan F, Bahat Z, Akpinar TS, Soyluk O, Erten N, Karan MA (2015) The relationship of body mass index and the functional status of community-dwelling female older people admitting to a geriatric outpatient clinic. Aging Clin Exp Res 27(3):303-308. https://doi.org/10.1007/ s40520-014-0291-2

35. Saka B, Ozkaya H, Karisik E, Akin S, Akpinar TS, Tufan F, Bahat G, Dogan H, Horasan Z, Cesur K, Erten N, Karan MA (2016) Malnutrition and sarcopenia are associated with increased mortality rate in nursing home residents: a prospective study. European Geriatric Medicine 7(3):232-238
36. Bahat G, Kilic C, Altinkaynak M, Akif KM (2020) Comparison of standard versus population-specific handgrip strength cut-off points in the detection of probable sarcopenia after launch of EWGSOP2. Aging Male 23(5):1564-1569. https://doi.org/10. 1080/13685538.2020.1870038

37. Bahat G, Kilic C, Ozkok S, Ozturk S, Karan MA (2021) Associations of sarcopenic obesity versus sarcopenia alone with functionality. Clin Nutr 40(5):2851-2859. https://doi.org/10.1016/j.clnu. 2021.04.002

38. Halil M, Ulger Z, Varlı M, Döventaş A, Oztürk GB, Kuyumcu ME, Yavuz BB, Yesil Y, Tufan F, Cankurtaran M, Saka B, Sahin S, Curgunlu A, Tekin N, Akçiçek F, Karan MA, Atlı T, Beger T, Erdinçler DS, Arıŏgul S (2014) Sarcopenia assessment project in the nursing homes in Turkey. Eur J Clin Nutr 68(6):690-694. https://doi.org/10.1038/ejcn.2014.15

39. Yilmaz O, Bahat G, Kucukdagli, Ozalp H, Cakmakci C, Karan MA (2018) Poliklinikte ayaktan başvuran yaşliların beslenme içeriği yeterli mi? 11. Akademik Geriatri Kongresi. 19-23 Nisan. Syf 131-132

40. Volkert D, Beck AM, Cederholm T, Cruz-Jentoft A, Goisser S, Hooper L, Kiesswetter E, Maggio M, Raynaud-Simon A, Sieber CC, Sobotka L, van Asselt D, Wirth R, Bischoff SC (2019) ESPEN guideline on clinical nutrition and hydration in geriatrics. Clin Nutr 38(1):10-47. https://doi.org/10.1016/j.clnu.2018.05.024

41. Shah M (2017) Role of nutrition inmusculoskeletal health. In: Nonpharmacological management of osteoporosis. Springer, pp 53-59. https://doi.org/10.1007/978-3-319-54016-0_5

42. Matsumoto H, Tanimura C, Kushida D, Osaka H, Kawabata Y, Hagino H (2020) FRAX score and recent fall history predict the incidence for sarcopenia in community-dwelling older adults: a prospective cohort study. Osteoporos Int 31(10):1985-1994. https://doi.org/10.1007/s00198-020-05447-4

43. Harvey NC, Odén A, Orwoll E, Lapidus J, Kwok T, Karlsson MK et al (2018) Falls predict fractures independently of FRAX probability: a Meta-Analysis of the Osteoporotic Fractures in Men (MrOS) study. J Bone Miner Res. 33(3):510-516. https://doi.org/ 10.1002/jbmr.3331

44. Bahat Öztürk G, K1lıç C, Bozkurt ME, Karan MA (2021) Prevalence and associates of fear of falling among community-dwelling older adults. J Nutr Health Aging 25(4):433-439. https://doi.org/ 10.1007/s12603-020-1535-9

45. Phelan EA, Mahoney JE, Voit JC, Stevens JA (2015) Assessment and management of fall risk in primary care settings. Med Clin North Am 99(2):281-293. https://doi.org/10.1016/j.mcna.2014. 11.004

46. Cuevas-Trisan R (2019) Balance problems and fall risks in older adults. Clin Geriatr Med 35(2):173-183. https://doi.org/10.1016/j. cger.2019.01.008

47. Thomas E, Battaglia G, Patti A, Brusa J, Leonardi V, Palma A et al (2019) Physical activity programs for balance and fall prevention in elderly: a systematic review. Medicine (Baltimore) 98(27):e16218. https://doi.org/10.1097/MD.0000000000016218

48. Erhan B, Ataker Y (2020) Rehabilitation of patients with osteoporotic fractures. J Clin Densitom 23(4):534-538. https://doi.org/ 10.1016/j.jocd.2020.06.006

49. Carter ND, Khan KM, McKay HA, Petit MA, Waterman C, Heinonen A, Janssen PA, Donaldson MG, Mallinson A, Riddell L, Kruse K, Prior JC, Flicker L (2002) Community-based exercise program reduces risk factors for falls in 65- to 75-year-old women with osteoporosis: randomized controlled trial. CMAJ 167(9):997-1004. Erratum in: CMAJ. 2003;168(2):152

50. Çergel Y, Topuz O, Alkan H, Sarsan A, Sabir AN (2019) The effects of short-term back extensor strength training in postmenopausal osteoporotic women with vertebral fractures: comparison of supervised and home exercise program. Arch Osteoporos 14(1):82. https://doi.org/10.1007/s11657-019-0632-z 
51. Murata K, Watanabe G, Kawaguchi S, Kanaya K, Horigome K, Yajima H, Morita T, Yamashita T (2012) Union rates and prognostic variables of osteoporotic vertebral fractures treated with a rigid external support. J Neurosurg Spine 17(5):469-475. https:// doi.org/10.3171/2012.7.SPINE122

52. Valentin GH, Pedersen LN, Maribo T (2014) Wearing an active spinal orthosis improves back extensor strength in women with osteoporotic vertebral fractures. Prosthet Orthot Int 38(3):232238. https://doi.org/10.1177/0309364613497393

53. Kutsal YG (2014) Yaşlıda osteoporoz. Kutsal YG, İrdesel J, Borman P, Ordu Gökkaya K (eds). Geriatrik Romatoloji. Öncü kitabevi s:351-366

54. Bahat G, Ilhan B, Erdogan T, Halil M, Savas S, Ulger Z, Akyuz F, Bilge AK, Cakir S, Demirkan K, Erelel M, Guler K, Hanagasi H, Izgi B, Kadioglu A, Karan A, Kulaksizoglu IB, Mert A, Ozturk S, Satman I, Sever MS, Tukek T, Uresin Y, Yalcin O, Yesilot N, Oren MM, Karan MA (2020) Turkish inappropriate medication use in older adults (TIME) criteria to improve prescribing in older adults: TIME-to-STOP/TIME-to-START. Eur Geriatr Med 11(3):491-498. https://doi.org/10.1007/s41999-020-00297-z

55. Cornelissen D, de Kunder S, Si L, Reginster JY, Evers S, Boonen A, Hiligsmann M, European Society for Clinical and Economic Aspect of Osteoporosis, Osteoarthritis and Musculoskeletal Diseases (ESCEO) (2020) Interventions to improve adherence to anti-osteoporosis medications: an updated systematic review. Osteoporos Int 31(9):1645-1669. https://doi.org/10.1007/ s00198-020-05378-0

56. Itkonen ST, Erkkola M, Lamberg-Allardt CJE (2018) Vitamin $\mathrm{D}$ fortification of fluid milk products and their contribution to vitamin $\mathrm{D}$ intake and vitamin $\mathrm{D}$ status in observational studies-a review. Nutrients 10(8):1054. https://doi.org/10.3390/nu10081054

57. Atar MÖ (2018) Yaşlilarda osteoporoz ve osteomalazi. Sonel Tur B (ed). Yaşlılar için fiziksel Rehabilitasyon. Yaşlılığa çok yönlü bakış. Hedef Kitabevi. Ankara, s:84-93

58. Vandenbroucke A, Luyten FP, Flamaing J, Gielen E (2017) Pharmacological treatment of osteoporosis in the oldest old. Clin Interv Aging 6(12):1065-1077. https://doi.org/10.2147/CIA. S131023

59. Institute of Medicine. Report at a glance. Report brief: dietary reference intakes for calcium and vitamin D, released 11/30/2010. http://www.iom.edu/Reports/2010/Dietary-Reference-IntakesforCalcium-and-Vitamin-D/Report-Brief.aspx. Accessed on Dec 01,2010

60. Bischoff-Ferrari HA, Dawson-Hughes B, Orav EJ, Staehelin HB, Meyer OW, Theiler R, Dick W, Willett WC, Egli A (2016) Monthly high-dose vitamin D treatment for the prevention of functional decline: a randomized clinical trial. JAMA Intern Med 176(2):175-183. https://doi.org/10.1001/jamainternmed.2015. 7148

61. Rizzoli R (2021) Vitamin D supplementation: upper limit for safety revisited? Aging Clin Exp Res. 33(1):19-24. https://doi. org/10.1007/s40520-020-01678-x

62. Fuggle NR, Cooper C, Harvey NC, Al-Daghri N, Brandi ML, Bruyere O, Cano A, Dennison EM, Diez-Perez A, Kaufman JM, Palacios S, Prieto-Alhambra D, Rozenberg S, Thomas T, Tremollieres F, Rizzoli R, Kanis JA, Reginster JY (2020) Assessment of cardiovascular safety of anti-osteoporosis drugs. Drugs 80(15):1537-1552. https://doi.org/10.1007/s40265-020-01364-2. PMID:32725307;PMCID:PMC7536167

63. Curtis EM, Cooper C, Harvey NC (2021) Cardiovascular safety of calcium, magnesium and strontium: what does the evidence say? Aging Clin Exp Res 33(3):479-494. https://doi.org/10.1007/ s40520-021-01799-x

64. http://www.pnmedycznych.pl/wp-content/uploads/2016/10/pnm_ 2016_777-80.pdf
65. Gregson CL, Hardcastle SA, Cooper C, Tobias JH (2013) Friend or foe: high bone mineral density on routine bone density scanning, a review of causes and management. Rheumatology (Oxford). 52(6):968-85. https://doi.org/10.1093/rheumatology/ ket007

66. Kanis JA, Cooper C, Rizzoli R, Reginster JY, Scientific Advisory Board of the European Society for Clinical and Economic Aspects of Osteoporosis (ESCEO) and the Committees of Scientific Advisors and National Societies of the International Osteoporosis Foundation (IOF) (2019) European guidance for the diagnosis and management of osteoporosis in postmenopausal women. Osteoporos Int 30(1):3-44. https://doi.org/10.1007/s00198-0184704-5. Erratum in: Osteoporos Int. 2020;31(1):209. Erratum in: Osteoporos Int. 2020;31(4):801

67. Meier C, Uebelhart B, Aubry-Rozier B, Birkhäuser M, BischoffFerrari HA, Frey D, Kressig RW, Lamy O, Lippuner K, Stute P, Suhm N, Ferrari S (2017) Osteoporosis drug treatment: duration and management after discontinuation. A position statement from the SVGO/ASCO. Swiss Med Wkly 147:w14484. https://doi.org/ 10.4414/smw.2017.14484

68. Camacho PM, Petak SM, Binkley N, Diab DL, Eldeiry LS, Farooki A, Harris ST, Hurley DL, Kelly J, Lewiecki EM, Pessah-Pollack R, McClung M, Wimalawansa SJ, Watts NB (2020) American Association of Clinical Endocrinologists/American College of Endocrinology Clinical Practice Guidelines for the Diagnosis and Treatment of Postmenopausal Osteoporosis-2020 update. Endocr Pract 26(Suppl 1):1-46. https://doi.org/10.4158/ GL-2020-0524SUPPL

69. Diab DL, Watts NB (2013) Bisphosphonate drug holiday: who, when and how long. Ther Adv Musculoskelet Dis 5(3):107-111. https://doi.org/10.1177/1759720X13477714

70. Bone HG, Hosking D, Devogelaer JP, Tucci JR, Emkey RD, Tonino RP, Rodriguez-Portales JA, Downs RW, Gupta J, Santora AC, Liberman UA (2004) Ten years' experience with alendronate for osteoporosis in postmenopausal women. N Engl J Med 350(12):1189-99. https://doi.org/10.1056/NEJMoa030897

71. Fink HA, MacDonald R, Forte ML, Rosebush CE, Ensrud KE, Schousboe JT, Nelson VA, Ullman K, Butler M, Olson CM, Taylor BC, Brasure M, Wilt TJ (2019) Long-term drug therapy and drug discontinuations and holidays for osteoporosis fracture prevention: a systematic review. Ann Intern Med 171(1):37-50. https://doi.org/10.7326/M19-0533

72. Kanis JA, Harvey NC, McCloskey E, Bruyère O, Veronese N, Lorentzon M, Cooper C, Rizzoli R, Adib G, Al-Daghri N, Campusano C, Chandran M, Dawson-Hughes B, Javaid K, Jiwa F, Johansson H, Lee JK, Liu E, Messina D, Mkinsi O, Pinto D, Prieto-Alhambra D, Saag K, Xia W, Zakraoui L, Reginster J (2020) Algorithm for the management of patients at low, high and very high risk of osteoporotic fractures. Osteoporos Int 31(1):1-12. https://doi. org/10.1007/s00198-019-05176-3. Erratum in: Osteoporos Int. 2020;31(4):797-798

73. Bone HG, Wagman RB, Brandi ML, Brown JP, Chapurlat R, Cummings SR et al (2017) 10 years of denosumab treatment in postmenopausal women with osteoporosis: results from the phase 3 randomised FREEDOM trial and open-label extension. Lancet Diabetes Endocrinol 5(7):513-523. https://doi.org/10.1016/ S2213-8587(17)30138-9

74. Li N, Cornelissen D, Silverman S, Pinto D, Si L, Kremer I, Bours S, de Bot R, Boonen A, Evers S, van den Bergh J, Reginster JY, Hiligsmann M (2021) An updated systematic review of cost-effectiveness analyses of drugs for osteoporosis. Pharmacoeconomics. 39(2):181-209. https://doi.org/10.1007/s40273-020-00965-9

75. Lems WF, Raterman HG (2017) Critical issues and current challenges in osteoporosis and fracture prevention. An overview of unmet needs. Ther Adv Musculoskelet Dis 9(12):299-316. https:// doi.org/10.1177/1759720X17732562 
76. Guggina P, Flahive J, Hooven FH, Watts NB, Siris ES, Silverman S, Roux C, Pfeilschifter J, Greenspan SL, Díez-Pérez A, Cooper C, Compston JE, Chapurlat R, Boonen S, Adachi JD, Anderson FA Jr, Gehlbach S, GLOW Investigators (2012) Characteristics associated with anti-osteoporosis medication use: data from the Global Longitudinal Study of Osteoporosis in Women (GLOW) USA cohort. Bone 51(6):975-80. https://doi.org/10.1016/j.bone. 2012.08.130

77. Klop C, Gibson-Smith D, Elders PJ et al (2015) Anti-osteoporosis drug prescribing after hip fracture in the UK: 2000-2010. Osteoporos Int 26(7):1919-1928. https://doi.org/10.1007/ s00198-015-3098-x

78. Ruggiero SL, Dodson TB, Fantasia J, Goodday R, Aghaloo T, Mehrotra B, O'Ryan F; American Association of Oral and Maxillofacial Surgeons (2014) American Association of Oral and Maxillofacial Surgeons position paper on medication-related osteonecrosis of the jaw--2014 update. J Oral Maxillofac Surg 72(10):1938-1956. https://doi.org/10.1016/j.joms.2014.04.031. Erratum in: J Oral Maxillofac Surg. 2015;73(7):1440. Erratum in: J Oral Maxillofac Surg. 2015;73(9):1879

79. Wan JT, Sheeley DM, Somerman MJ, Lee JS (2020) Mitigating osteonecrosis of the jaw (ONJ) through preventive dental care and understanding of risk factors. Bone Res 11(8):14. https://doi.org/ 10.1038/s41413-020-0088-1

80. Rosen HN (2021) Risks of bisphosphonate therapy in patients with osteoporosis. UpToDate. Access date: Sepember, 22, 2021

81. https://www.sheffield.ac.uk/NOGG\%20Guideline\%202017.pdf. Access date September 22, 2021

82. Kossioni AE (2018) The association of poor oral health parameters with malnutrition in older adults: a review considering the potential implications for cognitive impairment. Nutrients 10(11):1709. https://doi.org/10.3390/nu10111709

83. Yoshida M, Suzuki R, Kikutani T (2013) Nutrition and oral status in elderly people. Jpn Dent Sci Rev 50:9-14. https://doi.org/10. 1016/j.jdsr.2013.09.001

84. https://www.aegisdentalnetwork.com/cced/2020/05/teeth-in-geria tric-patients-to-restore-or-extract. Access date September 23, 2021

85. Symonds C, Kline G (2018) Warning of an increased risk of vertebral fracture after stopping denosumab. CMAJ 190(16):E485E486. https://doi.org/10.1503/cmaj.180115

86. Denosumab: drug information Lexicomp, UpToDate. 2021. Access date: March 2021

87. Eastell R, Rosen CJ, Black DM, Cheung AM, Murad MH, Shoback D (2019) Pharmacological management of osteoporosis in postmenopausal women: an endocrine society* clinical practice guideline. J Clin Endocrinol Metab 104(5):1595-1622. https:// doi.org/10.1210/jc.2019-00221

88. Liberman D, Cheung A (2015) A practical approach to osteoporosis management in the geriatric population. Can Geriatr J 18(1):29-34. https://doi.org/10.5770/cgj.18.129
89. Sleeman A, Clements JN (2019) Abaloparatide: a new pharmacological option for osteoporosis. Am J Health Syst Pharm 76(3):130-135. https://doi.org/10.1093/ajhp/zxy022

90. Reginster J, Bianic F, Campbell R, Martin M, Williams SA, Fitzpatrick LA (2019) Abaloparatide for risk reduction of nonvertebral and vertebral fractures in postmenopausal women with osteoporosis: a network meta-analysis. Osteoporos Int 30(7):1465-1473. https://doi.org/10.1007/s00198-019-04947-2

91. Paik J, Scott LJ (2020) Romosozumab: a review in postmenopausal osteoporosis. Drugs Aging 37(11):845-855. https://doi.org/10. 1007/s40266-020-00793-8. Erratum in: Drugs Aging. 2020

92. Rauner M, Taipaleenmäki H, Tsourdi E, Winter EM (2021) Osteoporosis treatment with anti-sclerostin antibodies-mechanisms of action and clinical application. J Clin Med 10(4):787. https://doi. org/10.3390/jcm 10040787

93. Wu CH, Kao IJ, Hung WC, Lin SC, Liu HC, Hsieh MH, Bagga S, Achra M, Cheng TT, Yang RS (2018) Economic impact and cost-effectiveness of fracture liaison services: a systematic review of the literature. Osteoporos Int 29(6):1227-1242. https://doi.org/ 10.1007/s00198-018-4411-2

94. Fuggle NR, Kassim Javaid M, Fujita M, Halbout P, DawsonHughes B, Rizzoli R, Reginster JY, Kanis JA, Cooper C (2020) Fracture risk assessment and How to implement a fracture liaison service. In: Falaschi P, Marsh D, editors. Orthogeriatrics: the management of older patients with fragility fractures [Internet]. Springer, Cham; 2021. Chapter 14

95. https://www.capturethefracture.org/index.php/map-of-best-pract ice. Access date September 22, 2021

96. Yu M, Downey C, Torralba KD (2020) The fracture liaison service to close the osteoporosis care gap: a leadership educational model for undergraduate and postgraduate trainees. Clin Rheumatol 39:619-626. https://doi.org/10.1007/s10067-019-04796-8

97. Walters S, Khan T, Ong T, Sahota O (2017) Fracture liaison services: improving outcomes for patients with osteoporosis. Clin Interv Aging 12:117-127. Published 2017. https://doi.org/10. 2147/CIA.S85551

98. Bahat G, Catikkas NM, Karan MA, Reginster JY (2021) Orthogeriatrics: a vital requirement for improving fragility fracture patient care internationally with particular reference to Turkey. Arch Osteoporos 16(1):103. https://doi.org/10.1007/ s11657-021-00967-w

99. Soulis G, Kotovskaya Y, Bahat G, Duque S, Gouiaa R, Ekdahl AW, Sieber C, Petrovic M, Benetos A (2021) Geriatric care in European countries where geriatric medicine is still emerging. Eur Geriatr Med. 12(1):205-211. https://doi.org/10.1007/ s41999-020-00419-7

Publisher's note Springer Nature remains neutral with regard to jurisdictional claims in published maps and institutional affiliations. 